\title{
Value of Platelet Function Testing in Monitoring Platelet Substitution
}

\author{
Oliver Meyer Holger Kiesewetter Abdulgabar Salama \\ Institut für Transfusionsmedizin, Charité Universitätsmedizin, Campus Virchow-Klinikum Berlin, Berlin, Germany
}

\section{Key Words}

Platelet function · Platelet concentrate $\cdot$ Transfusion $\cdot \mathrm{CCl}$

\section{Summary}

The use of platelet transfusion in the prevention and treatment of bleeding complications is still fiercely debated. To date, transfusions are usually monitored by measuring the post-transfusion platelet count and/or the corrected count increment. However, an increase in the platelet count does not necessarily correspond to an improvement in primary haemostasis. Although the response to platelet transfusions can be somewhat assessed by the physician treating the affected patient, the real effect remains frequently questionable. This review describes and discusses platelet function assays that might be used in the assessment of platelet transfusions.

\section{Introduction}

The availability of platelet concentrates has made a major contribution to modern clinical practice. In general, the substitution of platelets is the therapy of choice for preventing or treating bleeding episodes in patients with impaired platelet production and/or function. However, this treatment might be associated with risks and drawbacks, which include alloimmunization, transmission of bacterial and viral infections, allergic

\author{
Schlüsselwörter \\ Thrombozytenfunktion - Thrombozytenkonzentrat . \\ Transfusion $\cdot \mathrm{CCl}$
}

\section{Zusammenfassung}

Die Prävention und Behandlung von Blutungskomplikationen durch Thrombozytensubstitution wird weiter kontrovers diskutiert. In der Regel wird der Therapieerfolg einer Thrombozytensubstitution nur durch Messung des Thrombozytenanstiegs oder durch Berechung des "corrected count increment" bestimmt. Allerdings bedeutet der Anstieg der Thrombozytenzahl in der Zirkulation nicht zwangsläufig, dass es auch zu einer Verbesserung der primären Hämostase bei den Patienten kommt. Obwohl der behandelnde Arzt in der Regel eine Verbesserung der Blutungsneigung des Patienten nach Thrombozytentransfusion beobachten kann, bleibt der wahre therapeutische Effekt oft fraglich. Diese Übersichtsarbeit beschreibt und bewertet Methoden zur Bestimmung der Thrombozytenfunktion, die unter Umständen bei der Bestimmung des therapeutischen Effekts von Thrombozytentransfusionen hilfreich sein können.

reactions, transfusion related lung injury and substantial financial costs [1]. The decision regarding the use of platelets for transfusion must therefore be based on an assessment of risk versus benefit. To help in this risk-benefit analysis, several guidelines for platelet transfusions have been published (table 1), e.g. by the American Society of Clinical Oncology [2], the British Committee of Standards in Haematology [3, 4] and recently by the Joint Thrombocyte Working Party of the German Societies of Transfusion Medicine and Immunohaematol-

\begin{tabular}{llll}
\hline KARGER & ( 2007 S. Karger GmbH, Freiburg & & Dr. Oliver Meyer \\
Fax +497614520714 & Accessible online at: & & Institut für Transfusionsmedizin \\
$\begin{array}{l}\text { E-mail Information@Karger.de } \\
\text { www.karger.com }\end{array}$ & www.karger.com/tmh & Charité - Universitätsmedizin Berlin \\
& & Campus Virchow-Klinikum \\
& & Augustenburger Platz 1, 13353 Berlin, Germany \\
& & Tel. +49 30 450553-268, Fax -948, E-mail oliver.meyer@charite.de
\end{tabular}


ogy (DGTI), Thrombosis and Haemostasis Research (GTH) and Haematology and Oncology (DGHO) [5]. However, all these guidelines largely deal with indications for platelet transfusion and contribute very little to monitoring the therapeutic effect of this treatment. The scope of this review is to discuss laboratory methods that may be applicable to monitor platelet transfusion. Most importantly, these methods should be easy to handle, should generate results concomitant with the platelet transfusion and should be applied in a close-patient manner in all applicable hospital wards.

\section{Response to Platelet Transfusions}

Generally, the post-transfusion platelet recovery averages $60 \pm$ $15 \%$ of the transfused platelet dose [6]. About $30-35 \%$ of the transfused platelets are pooled in the spleen. Therefore, the recovery of platelets is decreased in hypersplenic patients while it may exceed $90 \%$ in asplenic individuals. The response to platelet transfusion may further be reduced by concurrent medical conditions such as bone marrow or stem cell transplantation, hepatomegaly, antibiotic therapy and a variety of other factors [7-10]. Furthermore, the post-transfusion platelet count is affected by the viability of the platelets transfused, the number of platelets in the platelet concentrate and the dilution of platelets in the patient's blood volume. Usually, the efficacy of platelet transfusions is evaluated from the corrected count increment $(\mathrm{CCI})$ that is calculated from the platelet increment $\left(\mathrm{PI} ; \times 10^{9} / \mathrm{l}\right)$, the body surface area (BSA; $\left.\mathrm{m}^{2}\right)$ and the platelet dose transfused $\left(\mathrm{PD} ; \times 10^{11}\right)[4]$ :

$$
\mathrm{CCI}=\frac{\mathrm{PI} \times \mathrm{BSA}}{\mathrm{PD}}
$$

A successful platelet transfusion is considered as a CCI of $>7.5 \times 10^{9} / 1$ at $1 \mathrm{~h}$ following transfusion and of $>4.5 \times 10^{9} / 1$ 20-24 h following transfusion [4]. However, the use of the CCI is not feasible in routine practice. In many cases, the exact platelet count in affected patients remains questionable due to technical difficulties associated with monitoring of very low platelet counts. In addition, the real content of the platelet concentrates is not provided by most blood services. Furthermore, in the case of prophylactic platelet transfusions in nonbleeding hospitalized patients it is reasonable to assess the response to platelet transfusions the morning following transfusion and is considered uncommon to measure the platelet count $1 \mathrm{~h}$ post transfusion. Basically, it is completely impracticable to measure the 1-hour and 20-hour post-transfusion CCI in almost all outpatients. Since an improvement in platelet count following platelet transfusion may not necessarily indicate an improvement in platelet function or restoration of primary haemostatic capacity, the application of objective laboratory assays addressing these parameters may help to provide a better assessment of platelet transfusion outcome than the CCI.

\section{Platelet Function Assays}

\section{Bleeding Time}

To assess the improvement of platelet-vessel wall interactions, the skin bleeding time (SBT) as described by Ivy et al. [11] may be used following platelet transfusions. To obtain accurate and comparable results using this procedure, the SBT should be performed in a standardized manner on the forearm. The incision has to be reproducible in length, depth and direction. Therefore, a purpose-built deposable device should be used. Throughout the procedure, the capillary pressure should be standardized by using a sphygmomanometer cuff to the upper arm, inflated to a pressure of $40 \mathrm{~mm} \mathrm{Hg}$. The time to cessation of bleeding is measured, and identification of this end point is aided by removal of blood from the area by applying a swab every $15 \mathrm{~s}$, taking care not to touch the edge of the wound.

In addition to operator differences, the SBT is affected by several factors. These include an inverse linear relation between the platelet count and the SBT as well as a prolongation from thrombocytopenia alone at platelet counts less than $100,000 / \mu \mathrm{l}$ [12] and following ingestion of drugs that inhibit cyclooxygenase-1. The SBT may also be affected by other medications and dietary supplements without necessarily reflecting an increased risk of bleeding. In preoperative screening, the SBT has limited value because a prolonged SBT does not predict an increased bleeding risk $[13,14]$.

The SBT is time and personnel intensive. Furthermore, the incisions may lead to excessive bleeding in thrombocytopenic patient and infections in patients with impaired immune response (e.g. bone marrow / stem cell transplantation, chemotherapy).

\section{Platelet Aggregation Test}

The classical platelet function assay is the assessment of the ex vivo platelet function by light transmission aggregometry [15]. The method is usually applied in patients with a history suggestive of a disorder of primary haemostasis (e.g. Glanzmann's thrombasthenia, Bernard-Soulier syndrome, von Willebrand's disease). Platelet rich plasma (PRP) or, more physiologically, whole blood [16] is incubated in a cuvette containing a metal stir bar. Upon incubation with different platelet stimulating substances (e.g. adenosine diphosphate, epinephrine, collagen, arachidonic acid, ristocetin, thrombin) platelets change their shape from discs to a more rounded form, leading to a small decrease in light transmission. Subsequently, the platelets aggregate leading to an increase of light transmission [17] or of electrical resistance [16]. The platelet aggregation test is affected by very low platelet counts and is not considered reliable at platelet counts below $100 \times 10^{9} / 1$ in the PRP [17]. Therefore, this assay cannot be applied in thrombocytopenic patients. Furthermore, the assay is laborious, time consuming and requires a high degree of expertise to perform and interpret the results [18]. 
Table 1. Recommendations for platelet transfusions by the Joint Thrombocyte Working Party of the German Societies of Transfusion Medicine and Immunohaematology (DGTI), Thrombosis and Haemostasis Research (GTH), and Haematology and Oncology (DGHO) [5]

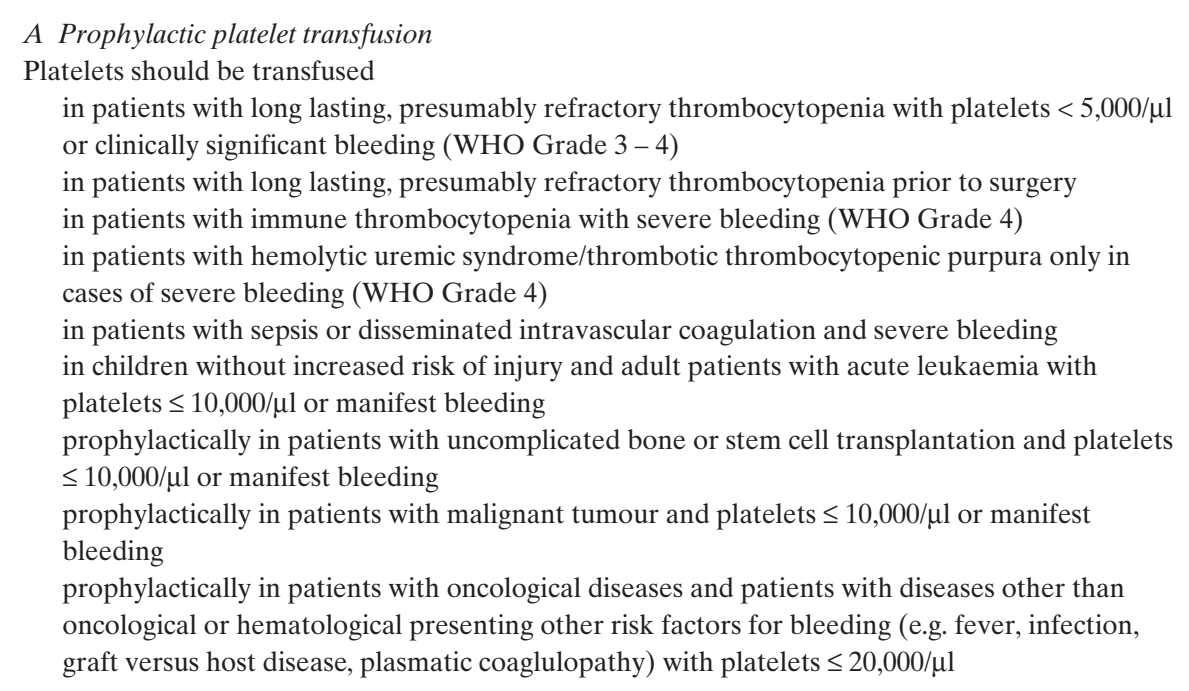

B Invasive diagnostic procedures

Platelets should be transfused

prior to lumbar puncture and platelets $\leq 50,000 / \mu \mathrm{l}$ in life threatening situations lumbar punctures may be undertaken with lower platelet counts prior to transjugular liver puncture and platelets $<10,000 / \mu \mathrm{l}$ prior to transcutaneous liver puncture and platelets $<50,000 / \mu \mathrm{l}$ prior to joint aspiration and platelets $<20,000 / \mu \mathrm{l}$ prior to large dental procedures and platelets $<30,000 / \mu \mathrm{l}$ prior to gastroscopy with biopsy and platelets $<20,000 / \mu$ l prior to trans bronchial biopsy and platelets $<50,000 / \mu \mathrm{l}$ prior to angiography (not performed for diagnosis of arterial thromboembolic events!) and platelets $<20,000 / \mu$ l

Platelets should not be transfused prior to bone marrow biopsy

\section{Flow Cytometry}

Monoclonal antibodies to a variety of platelet markers are available and allow for the assessment of platelet activation and secretion as well as for the quantitation of constitutively expressed platelet membrane proteins in patients with congenital deficiencies $[19,20]$. Furthermore, flow cytometry seems to be applicable for the assessment of the amount of transfused platelets in patients with congenital deficiencies of platelet membrane proteins [21, 22]. By using fluorescence resonance energy transfer, this method seems to be capable to investigate ligand induced conformational changes of glycoproteins or interactions with other cells [23, 24], but these assays are only applicable in specialized laboratories. Furthermore, flow cytometry does not provide any information about the overall haemostasis. Furthermore, flow cytometry requires technical equipment that is not broadly available.

\section{Thrombelastography}

Thrombelastography (TEG ${ }^{\circledR}$, Haemoscope Corporation, IL, USA) provides a graphical representation of the fibrin polymerization process by recording the viscoelastic changes occurring during blood coagulation [25]. Thus, TEG and the recently introduced rotational thrombelastogram $\left(\right.$ ROTEM $^{\circledR}$, Pentapharm GmbH, Munich, Germany) enable for the complete evaluation of clot initiation, clot formation and clot stability. TEG and ROTEM have mainly been used for the monitoring of blood component therapy during liver transplantation [26] and later on for cardiac surgery [27]. Both methods can be used in a bed-side manner and are capable of delivering an overview of platelet function, coagulation proteases and inhibitors, and the fibrinolytic system within $30 \mathrm{~min}$ [28]. However, both methods are difficult to standardize and require a high level of expertise to interpret the results. Further- 
more, the sensitivity of the method in regards to measuring platelet function in thrombocytopenic patients is quite low [29]. A recently described whole blood flow method measuring increased thrombus formation and thrombin generation seems to have a higher sensitivity than thrombelastography, and it seems to be feasible for the assessment of platelet transfusion therapy, but it requires complex microscopic evaluation and is therefore difficult to use in a bed-side manner [29].

\section{$P F A-100^{\circledR}$}

The PFA-100 ${ }^{\circledR}$ (Dade-Behring, Marburg, Germany) was developed to assess platelet and von Willebrand factor (VWF) function in an automated assay that may have a better reproducibility than the SBT $[30,31]$. It utilizes test cartridges containing a collagen/epinephrine or collagen/ADP membrane with a $147 \mu \mathrm{m}$ wide central aperture. Citrated whole blood is aspirated under high shear $(5,000-6,000 / \mathrm{s})$ from the sample reservoir through the capillary tube onto the membrane. Primarily, the platelets begin to adhere onto the membrane via VWF interactions with glycoprotein (GP) Ib and then aggregate due to GPIIb-IIIa-fibrinogen interactions. These processes lead to an occlusion of the aperture normally within 1-3 min from test initiation. The PFA-100 monitors the drop in flow rate, the volume of blood aspirated through the aperture and the final closure time. The handling of the device is relatively simple, rapid and easy to learn. Major disadvantages of the system are that the results are sensitive to large number of variables (e.g. platelet count, haematocrit, drug effects, platelet receptor defects, VWF defects, release defects and granular defects) that are also known to affect the platelet function in vivo [32]. Platelet counts $<80 \times 10^{9} / 1$ and a haematocrit $<30 \%$ lead to a prolongation of the closure time [ 30 , 31]. Therefore, the usefulness of the PFA-100 for the assessment of platelet transfusions may be questionable.

Using a modified Thrombostat 4000 device (VDG, Seeon, Germany) [33], the prototype of the PFA-100, Kretschmer et al. [34] demonstrated the usefulness of this device in a small and homogenous group of 16 patients that were investigated prior and up to 5 days following platelet transfusion. Using the same device, Eriksson et al. [35] investigated 36 patients with chemotherapy-induced thrombocytopenia prior to transfusion and both 10-30 min and $24 \mathrm{~h}$ following platelet transfusion. A measurable reduction closure time was observed in approximately $90 \%$ of the investigated patients $10-30 \mathrm{~min}$ following transfusion. The improvement in closure time decreased with the time after transfusion and the storage time of the platelet concentrates. Recently, Salama et al. [36] demonstrated that the PFA-100 provided a better indication of outcome after platelet transfusion than the CCI. The post-transfusion response of 31 patients who received 35 platelet transfusions was divided in two subgroups. In one group, platelet transfusions resulted in significant shortening (defined as reduction in closure time $>40 \mathrm{~s}$ ) or normalization in closure times $(n=17)$, whereas in the second group $(n=18)$ no change or prolongation of the closure time was observed. Although testing the platelet function provided a better indication of transfusion response than the post-transfusion CCI, the application of the PFA-100 was without any potential benefit in about $50 \%$ of the investigated patients [35]. The latter finding may be related to low platelet counts and/or low haematocrit values of the investigated patients.

\section{Cone and Plate(let) Analyzer}

The cone and plate(let) analyzer (Impact- $\mathrm{R}^{\circledR}$; DiaMed, Cressier s/Morat, Switzerland) was developed for the investigation of platelet disposition under defined shear conditions $(2,050 / \mathrm{s})[37,38]$. Citrated whole blood is placed onto a polystyrene plate and subjected to flow using a rotating teflon cone that induces a constant fluid shear stress over the entire plate surface. Subsequently, the wells are washed, stained with May-Gruenwald stain and analyzed with an inverted light microscope that is connected to an image analysis system. Using this system, platelet adhesion and aggregation can be evaluated by examining the percentage of total area covered with platelets (surface coverage), and the mean size of surface bound objects (both single platelets and platelet aggregates). The test is very simple and requires a very small volume of blood $(0.2 \mathrm{ml})$. In our experience, the test demonstrated reproducible results, even in patients with platelet counts $<30 \times$ $10^{9} / 1$. Furthermore, the results of the Impact-R are independent of other variables (e.g. haematocrit and coagulation factors). Panzer et al. [22] investigated the function of transfused platelets in a 7-year-old girl with Bernard-Soulier syndrome, an autosomal recessive bleeding disorder. This syndrome is characterized by moderate thrombocytopenia, large dysfunctional platelets and a defect in VWF dependent platelet adhesion due to a defect in the biosynthesis of the GPIb-IX-V complex, the primary receptor for VWF [39]. The platelets of the patient described showed an absence of GP42b (GPIb alpha) by flow cytometry and did not respond to high shear stress of the Impact-R. For up to 1 week following platelet transfusion, transfused platelets could be differentiated by flow cytometry, and a normal response was documented by the Impact-R. Furthermore, the patient did not suffer from bleeding complications during this period. Further studies are under way to evaluate the value of this system in monitoring platelet transfusion, and the results seem to be promising.

\section{Conclusion}

Platelet transfusion is the standard therapy of choice for preventing or treating bleeding complications in thrombocytopenic patients, e.g. after chemotherapy. Generally, the effect of platelet transfusion is evaluated from the post-transfusion platelet count or the CCI. However, these values report only the presence of transfused platelets in the circulation of the transfused patient, but do not evaluate their haemostatic ac- 
tivity. The SBT measures platelet-vessel wall interactions, but it is a very incriminating procedure for the patients and does not accurately predict a bleeding risk. Classical platelet function assays such as the platelet aggregation test, flow cytometry and thrombelastography cannot be used because they are demanding on a technical and personnel level, require a high degree of expertise in interpretation of the results and are mostly unusable in thrombocytopenic patients. The commercially available device PFA-100 is very sensitive to low haematocrit and low platelet counts that are present in almost all patients requiring platelet transfusion. Due to these disadvantages, the device is not suitable for the monitoring of platelet transfusions. The Impact- $\mathrm{R}$ is a whole blood method that is rapid and easy to handle. It permits the evaluation of platelet function in a bed-side manner, but there has only been one study to date which has demonstrated the usefulness of Impact-R in monitoring platelet substitution therapy.

At this point in time, a general recommendation to monitor platelet function in context with platelet transfusion cannot be given. However, the Impact-R is capable of measuring platelet adhesion and aggregation independently from variables such as platelet count, haematocrit, and activity of coagulation factors. Therefore, this device seems to be quite promising for the monitoring of platelet transfusion therapy.

\section{References}

1 McCullough J, Steeper TA, Connelly DP, Jackson B, Huntington S, Scott EP: Platelet utilization in a university hospital. JAMA 1988;259:2414-2418.

$\checkmark 2$ Schiffer CA, Anderson KC, Bennett CL, Bernstein S, Elting LS, Goldsmith M, Goldstein M, Hume H, McCullough JJ, McIntyre RE, Powell BL, Rainey JM, Rowley SD, Rebulla P, Troner MB, Wagnon AH: Platelet transfusion for patients with cancer: clinical practice guidelines of the American Society of Clinical Oncology. J Clin Oncol 2001;19: 1519-1538.

3 Murphy MF, Brozovic B, Murphy W, Ouwehand W, Waters AH: Guidelines for platelet transfusions. British Committee for Standards in Haematology, Working Party of the Blood Transfusion Task Force. Transfus Med 1992;2:311-318.

4 BCSH: Guidelines for the use of platelet transfusions. Br J Haematol 2003;122:10-23.

$>5$ Greinacher A, Kiefel V, Klüter H, Kroll H, Pötzsch B, Riess H: Empfehlungen zur Thrombozytentransfusion der Thrombozyten-Arbeitsgruppe der DGTI, GTH und DGHO. Transfus Med Hemother 2006;33:528-543.

6 Hanson SR, Slichter SJ: Platelet kinetics in patients with bone marrow hypoplasia: evidence for a fixed platelet requirement. Blood 1985;66:1105-1109.

$\checkmark 7$ Doughty HA, Murphy MF, Metcalfe P, Rohatiner AZ, Lister TA, Waters AH: Relative importance of immune and non-immune causes of platelet refractoriness. Vox Sang 1994;66:200-205.

8 Bishop JF, McGrath K, Wolf MM, Matthews JP, De Luise T, Holdsworth R, Yuen K, Veale M, Whiteside MG, Cooper IA, et al: Clinical factors influencing the efficacy of pooled platelet transfusions. Blood 1988;71:383-387.

9 Friedberg RC, Donnelly SF, Boyd JC, Gray LS, Mintz PD: Clinical and blood bank factors in the management of platelet refractoriness and alloimmunization. Blood 1993;81:3428-3434.

10 Bock M, Muggenthaler KH, Schmidt U, Heim MU: Influence of antibiotics on posttransfusion platelet increment. Transfusion 1996;36:952-954.

11 Ivy AC, Nelson D, Bucher MS: The standardization of certain factors in the cutaneous 'venostasis' bleeding time technique. J Lab Clin Med 1941;26: 1812-1822.

12 Harker LA, Slichter SJ: The bleeding time as a screening test for evaluation of platelet function. N Engl J Med 1972;287:155-159.

13 Rodgers RP, Levin J: A critical reappraisal of the bleeding time. Semin Thromb Hemost 1990;16: $1-20$.
14 Lind SE: The bleeding time does not predict surgical bleeding. Blood 1991;77:2547-2552.

15 Born GV: Aggregation of blood platelets by adenosine diphosphate and its reversal. Nature 1962;194: 927-929.

16 Cardinal DC, Flower RJ: The electronic aggregometer: a novel device for assessing platelet behavior in blood. J Pharmacol Methods 1980;3: 135-158.

17 Rand ML, Leung R, Packham MA: Platelet function assays. Transfus Apher Sci 2003;28:307-317.

18 The British Society for Haematology BCSH Haemostasis and Thrombosis Task Force: Guidelines on platelet function testing. J Clin Pathol 1988;41:1322-1330.

19 Michelson AD, Barnard MR, Krueger LA, Frelinger AL 3rd, Furman MI: Evaluation of platelet function by flow cytometry. Methods 2000; 21:259-270.

20 Peerschke EI: The laboratory evaluation of platelet dysfunction. Clin Lab Med 2002;22:405-420.

21 Nurden A, Combrie R, Nurden P: Detection of transfused platelets in a patient with Glanzmann thrombasthenia. Thromb Haemost 2002;87:543544.

22 Panzer S, Eichelberger B, Koren D, Kaufmann K, Male C: Monitoring survival and function of transfused platelets in Bernard-Soulier syndrome by flow cytometry and a cone and plate(let) analyzer (Impact-R). Transfusion 2007;47:103-106.

23 Seyfarth HJ, Koksch M: Fibrinogen receptor antagonists induce conformational changes of the human platelet glycoprotein IIb. Cytometry B Clin Cytom 2004;62:14-24.

24 Klouche M: Diagnostic methods for platelet function analysis. Transfus Med Hemother 2007;34: 20-32.

25 Hartert H: Blutgerinnunsstudien mit der Thrombelastographie, einem neuen Untersuchungsverfahren. Klin Wochenschr 1948;26.

26 Kang YG, Martin DJ, Marquez J, Lewis JH, Bontempo FA, Shaw BW Jr, Starzl TE, Winter PM: Intraoperative changes in blood coagulation and thrombelastographic monitoring in liver transplantation. Anesth Analg 1985;64:888-896.

27 Spiess BD, Gillies BS, Chandler W, Verrier E Changes in transfusion therapy and reexploration rate after institution of a blood management program in cardiac surgical patients. J Cardiothorac Vasc Anesth 1995;9:168-173.

28 Luddington RJ: Thrombelastography/thromboelastometry. Clin Lab Haematol 2005;27:81-90.
29 Cauwenberghs S, Feijge MA, Theunissen E, Heemskerk JW, van Pampus EC, Curvers J: Novel methodology for assessment of prophylactic platelet transfusion therapy by measuring increased thrombus formation and thrombin generation. $\mathrm{Br} \mathrm{J}$ Haematol 2007;136:480-490.

30 Kundu SK, Heilmann EJ, Sio R, Garcia C, Davidson RM, Ostgaard RA: Description of an in vitro platelet function analyzer - PFA-100. Semin Thromb Hemost 1995;21(suppl 2):106-112.

31 Jilma B: Platelet function analyzer (PFA-100): a tool to quantify congenital or acquired platelet dysfunction. J Lab Clin Med 2001;138:152-163.

32 Harrison P: The role of PFA-100 testing in the investigation and management of haemostatic defects in children and adults. Br J Haematol 2005;130: 3-10.

33 Kratzer MA, Born GV: Simulation of primary haemostasis in vitro. Haemostasis 1985;15:357-362.

34 Kretschmer V, Huss B, Dietrich G, Heymanns J, Pflüger K-H: Determination of bleeding risk in thrombcytopenic patients receiving platelet substitution. Transfus Sci 1993;14:27-34.

35 Eriksson L, Kristensen J, Olsson K, Bring J, Högman CF: Evaluation of platelet function using the in vitro bleeding time and corrected count increment of transfused platelets. Comparison between platelet concentrates derived from pooled buffy coates and apheresis. Vox Sang 1996;70:69-75.

-36 Salama ME, Raman S, Drew MJ, Abdel-Raheem M, Mahmood MN: Platelet function testing to assess effectiveness of platelet transfusion therapy. Transfus Apher Sci 2004;30:93-100.

37 Varon D, Dardik R, Shenkman B, Kotev-Emeth S, Farzame N, Tamarin I, Savion N: A new method for quantitative analysis of whole blood platelet interaction with extracellular matrix under flow conditions. Thromb Res 1997;85:283-294.

38 Shenkman B, Savion N, Dardik R, Tamarin I, Varon D: Testing of platelet deposition on polystyrene surface under flow conditions by the cone and plate(let) analyzer: role of platelet activation, fibrinogen and von Willebrand factor. Thromb Res 2000;99:353-361.

39 Nurden AT: Qualitative disorders of platelets and megakaryocytes. J Thromb Haemost 2005;3:17731782 . 